\title{
Tinea capitis among children at one suburban primary school in the City of Maputo, Mozambique
}

\author{
Tinea capitis entre as crianças de uma escola primária suburbana \\ na Cidade Maputo, Mozambique
}

Mohsin M. Sidat ${ }^{1}$, Della Correia ${ }^{2,3}$ and Titos Paulo Buene ${ }^{2,3}$

\begin{abstract}
This study evaluated the prevalence of Tinea capitis among schoolchildren at one primary school and also identified the causative agents. Scalp flakes were collected from children presenting clinical signs suggestive of Tinea capitis. Dermatophytes were identified by following standard mycological procedures. This study found a clinical prevalence of Tinea capitis of 9.6\% (110/1149). The dermatophytes isolated were Microsporum audouinii, Trichophyton violaceum, and Trichophyton mentagrophytes. The most prevalent causative agent in this study was Microsporum audouinii, thus confirming the findings from previous cross-sectional studies carried out in the City of Maputo.
\end{abstract}

Key-words: Tinea capitis. Ringworm. Dermatophytosis. Schoolchildren.

\section{RESUMO}

O estudo avaliou a prevalência da Tinea capitis na população estudantil duma Escola Primária e também identificou os agentes causais responsáveis. Escamas do couro cabeludo foram recolhidas das crianças apresentando sinais clínicos sugestivos de Tinea capitis. Dermatófitos foram identificados seguindo procedimentos micológicos padronizados. Este estudo encontrou uma prevalência clínica de Tinea capitis de 9,6\% (110/1149). Os dermatófitos isolados foram Microsporum audouinii, Trichophyton violaceum $e$ Trichophyton mentagrophytes. $O$ agente causal mais prevalente neste estudo foi Microsporum audouinii confirmando os achados dos estudos transversais anteriores levados a cabo na Cidade de Maputo.

Palavras-chaves: Tinea capitis. Tinha. Dermatofitose. Crianças escolares.

Tinea capitis is a fungal infection of the scalp hair follicles and the surrounding skin caused by dermatophytes ${ }^{4}$. This condition, also known as scalp ringworm or dermatophytosis of the scalp ${ }^{2}$ is predominantly seen among prepubescent children ${ }^{24}$. The prevalence of Tinea capitis and the predominance of its different etiological agents vary in accordance with the geographical regions as well as the methods used to assess the affected individuals ${ }^{6}$. Moreover, the predominant dermatophytes causing Tinea capitis in a given geographic region can also change over time ${ }^{2}$. The incidence of Tinea capitis in developed countries has clearly declined following improvements in socioeconomic conditions, introduction of griseofulvin for treatment and also introduction of adequate school surveillance programs ${ }^{2}$. In Africa, however, Tinea capitis continues to be an important public health problem, where it has been reported to affect $10 \%$ to $30 \%$ of school-age children ${ }^{10}$.

The earliest study relating to Tinea capitis carried out in Mozambique was published in $1961^{9}$, and reported an overall prevalence of 3.6\% (421/11565) among native children, with Trichophyton violaceum identified as the predominant causal agent countrywide, while Microsporum audouinii was predominant in Maputo (previously named Lourenço Marques). Subsequently, very few small studies were carried out, mainly in Maputo, the most recent of which was published in $2001^{1}$. Microsporum audouinii was also the predominant etiological agent of Tinea capitis in all of these recent studies ${ }^{157}$. Because large outbreaks often occur in schools or other places where children are congregated ${ }^{2}$, and because there was an ongoing inspection program for schools, as part of the activities carried out by the Community Health Department of the Mozambican Ministry of Health, we conveniently selected one suburban school to assess the prevalence of Tinea capitis among schoolchildren, as the study population and also to identify their causative agents.

This study was carried out in one suburban primary school in the City of Maputo (for ethical reasons the school name has

\footnotetext{
1. Department of Community Health, Faculty of Medicine, University Eduardo Mondlane, Maputo, Mozambique. 2. School Health Program, Department of Community Health, Ministry of Health, Maputo, Mozambique. 3. Laboratory of Parasitology, Faculty of Medicine, University Eduardo Mondlane, Maputo, Mozambique.

For financing this study through the Open Fund for Scientific Investigation of the Scientific Department of the Eduardo Mondlane University, Maputo, Mozambique.

Address to: Dr Mohsin M. Sidat. Dept of Community Health/FM/UEM. PO Box 257, Maputo, Mozambique.

Tel: 2581 32-5227/328076; Fax: $258132-5255$

e-mail:mmsidat@yahoo.com.br

Recebido em: 03/05/07

Aceito em: 20/06/07
} 
been kept confidential in this paper) during November 2001. The study was integrated within the routine health surveillance activities of the School Health Program of the Community Health Department of the Mozambican Ministry of Health. However, this particular school was chosen because of its location in one of the poorest suburbs of Maputo and its easy accessibility for the research team. Consent to carry out this study was obtained from the School Director and parents were also informed. We only examined children attending the school in first and second shifts (i.e. morning shifts, because the children attending these shifts are younger than those in the afternoon and evening shifts, who are much older). Samples from the scalp were obtained only from children presenting lesions suggestive of Tinea capitis and who verbally consented. This study was approved by the Scientific Department of the Eduardo Mondlane University and financially supported by SIDA/SAREC.

Samples for laboratory examination were obtained using a sterile swab that was rubbed over lesions (rubbing was confined to the affected areas). The swabs were subsequently placed in labeled sterile plastic tubes for transportation to the Parasitology Laboratory of the School of Medicine of the Eduardo Mondlane University, in Maputo, Mozambique. The samples were processed on the same day. The method of rubbing with swabs was used because of its practicality in this type of study and also because it has been reported to give good positive yields, even from clinically normal scalps ${ }^{3}$.

All the children who presented with suspected Tinea capitis lesions were treated with $10 \mathrm{mg} / \mathrm{kg} /$ day of griseofulvin, for a period of four weeks. An instruction letter for the parents and/ or guardians was given to each schoolchild who received the treatment, explaining briefly the nature of the infection and the need for adherence to the treatment so as to cure the infection.

At the laboratory, the swabs were passed through standard mycological culturing medium. The cultures were incubated at between $28^{\circ} \mathrm{C}$ and $30^{\circ} \mathrm{C}$ and were regularly checked for four weeks. Dermatophyte identification was performed on the basis of macroscopic and microscopic characteristics ${ }^{3}$. To observe the microscopic characteristics, the adhesive tape method was used $^{3}$. All data collected from the participants were entered into a database created specifically for this study using Epi-Info 6.04. All data were kept confidential at all stages of the study. Because of the small sample and descriptive nature of the study, no statistical analysis was performed.

We examined a total of 1,149 schoolchildren ( 579 from the first and 570 from the second shift) at this suburban school. About $47.8 \%(549 / 1,149)$ were male children. We found 110 children with suspected Tinea capitis based on clinical lesions, but only 108 gave their verbal consent to undergo sampling. The clinical prevalence of Tinea capitis at this suburban primary school was therefore $9.6 \%(110 / 1,149)$.

About $92.7 \%$ (100/108) of the mycological cultures yielded positive results. The prevalence of positive cultures was higher for scalp samples obtained from children aged between 5 and 10 years of age $(61.2 \% ; 66 / 108)$. Out of the total of 100 positive cultures, 84 resulted in single dermatophyte isolates and 16 resulted in two or more dermatophyte isolates. The most common dermatophytes isolated were Microsporum audouinii, Trichophyton violaceum and Trichophyton mentagrophytes. In the age group from 5 to 10 years, the main isolate was Microsporum audouinii, and in the group from 11 to 15 years it was Trichophyton violaceum (Table 1). Among the positive cultures with two or more isolates, we found 15 cultures with two dermatophyte isolates: 12 cultures with Microsporum audouinii and Trichophyton violaceum; and three cultures with Trichophyton violaceum and Trichophyton mentagrophytes. We found only one positive culture with three different dermatophyte isolates, which were Microsporum audouinii, Trichophyton violaceum and Trichophyton mentagrophytes. The majority of the multiple isolates were obtained from scalp samples taken from male schoolchildren (Table 2). The average age of the children with multiple isolates was 10.5 years.

Table 1-Relationship between age groups and the dermatophyte species isolated.

\begin{tabular}{|c|c|c|c|c|c|c|c|}
\hline \multirow{3}{*}{$\begin{array}{l}\text { Age } \\
\text { groups } \\
\text { (years) }\end{array}$} & \multicolumn{2}{|c|}{$\begin{array}{c}\text { Trichophyton } \\
\text { violaceum }\end{array}$} & \multicolumn{2}{|c|}{$\begin{array}{c}\text { Microsporum } \\
\text { audouinii }\end{array}$} & \multicolumn{2}{|c|}{$\begin{array}{c}\text { Trichophyton } \\
\text { mentagrophytes }\end{array}$} & \multirow{3}{*}{ Total } \\
\hline & \multicolumn{2}{|c|}{ frequency } & \multicolumn{2}{|c|}{ frequency } & \multicolumn{2}{|c|}{ frequency } & \\
\hline & $\mathrm{n}^{\mathrm{O}}$ & $\%$ & $\mathrm{n}^{0}$ & $\%$ & $\mathrm{n}^{0}$ & $\%$ & \\
\hline $5-10$ & 30 & 25.6 & 41 & 35.0 & 6 & 5.1 & 77 \\
\hline $11-15$ & 21 & 18.0 & 19 & 16.3 & 0 & 0.0 & 40 \\
\hline Total & 51 & 43.6 & 60 & 51.3 & 6 & 5.1 & 117 \\
\hline
\end{tabular}

Table 2 - Relationship between age, sex and dermatophytes isolated from scalp samples taken from the schoolchildren who presented multiple isolates of dermatophytes.

\begin{tabular}{lccc}
\hline $\begin{array}{l}\text { Record } \\
\text { number }\end{array}$ & $\begin{array}{c}\text { Age } \\
\text { (years) }\end{array}$ & Sex & Dermatophytes isolated \\
\hline 38 & 11 & M & Microsporum audouinii + Trichophyton violaceum \\
47 & 13 & M & Microsporum audouinii + Trichophyton violaceum \\
55 & 14 & M & Microsporum audouinii + Trichophyton violaceum \\
56 & 12 & M & Microsporum audouinii + Trichophyton violaceum \\
61 & 11 & M & Microsporum audouinii + Trichophyton violaceum \\
63 & 9 & F & Microsporum audouinii + Trichophyton violaceum \\
64 & 13 & M & Microsporum audouinii + Trichophyton violaceum \\
70 & 10 & M & Microsporum audouinii + Trichophyton mentagrophytes \\
72 & 7 & M & Microsporum audouinii + Trichophyton violaceum \\
84 & 10 & M & Microsporum audouinii + Trichophyton mentagrophytes \\
85 & 8 & M & Microsporum audouinii + Trichophyton mentagrophytes \\
87 & 9 & M & Microsporum audouinii + Trichophyton violaceum \\
90 & 7 & F & Microsporum audouinii + Trichophyton violaceum \\
100 & 7 & F & Microsporum audouinii + Trichophyton violaceum \\
103 & 7 & F & Microsporum audouinii + Trichophyton violaceum \\
& & & Trichophyton mentagrophytes
\end{tabular}

\begin{tabular}{lccc}
106 & 9 & F & Microsporum audouinii + Trichophyton violaceum \\
\hline M: male & F: female &
\end{tabular}

Tinea capitis has been reported to occur more commonly in Africa, where its prevalence ranges from $10 \%$ to $30 \%{ }^{10}$. Our study found a prevalence of clinically suggestive Tinea capitis of $9.6 \%$ and, although this is close to what has been reported in Africa, it is relatively high when compared to the $3.6 \%(421 / 11,565)$ that was reported in Mozambique previously, in 1961 ${ }^{9}$. This high 
prevalence now found might be due to the characteristics of our sample, which represented children attending school. This distinguishes our study from the study carried out in $1961^{9}$, in which the children were examined within a community setting and many of them were not attending schools or any other institutions, and thus did not have close contact with other children. Tinea capitis is regarded as a highly contagious fungal infection ${ }^{8}$ and thus school outbreaks can occur. Therefore, the prevalence found in the present study might to some extent be the result from an ongoing outbreak of Tinea capitis at the school studied.

The etiological agents for scalp ringworm found in this study were predominantly of anthropophilic type, namely Microsporum audouinii and Trichophyton violaceum. Only a few isolates of Trichophyton mentagrophytes were yielded in the present study and, interestingly, all the isolates of this zoophilic dermatophyte came from simultaneous cultures with other anthropophilic dermatophytes. The predominance of anthropophilic dermatophytes in a school setting could be responsible for perpetuating Tinea capitis among schoolchildren and also may explain the relatively high prevalence found in this study. It has been reported ${ }^{2}$ that fungal particles from anthropophilic dermatophytes are viable for months and are also found among asymptomatic carriers, i.e. individuals who do not show signs or symptoms of Tinea capitis but from whom dermatophytes can be isolated when samples of their hair and/or skin are cultured.

Although this study presents some valuable data, there are some limitations that seem relevant to mention here. Firstly, the nature of the study sample and its size constitute an important limitation on extrapolation of the prevalence found in this study, to a community level. Secondly, in this study only those children with clinical signs of Tinea capitis were included in the study and thus it is not possible to assess the prevalence of dermatophyte carriers, as was done in other studies ${ }^{1}$. Finally, the cross-sectional nature of the study does not allow more detailed analysis of the prevalence of Tinea capitis over time and in different climatic seasons. However, it confirms the findings from previous studies that Microsporum audouinii continues to be a prevailing species of Tinea capitis in the City of Maputo ${ }^{1579}$.

Although this single cross-sectional study is insufficient for inferring that Tinea capitis is a public health issue in Mozambique, the high prevalence found in this study gives a hint of its importance, particularly within primary school settings. Therefore, periodic surveillance of Tinea capitis among schoolchildren might be important. Furthermore, because of the ease of identifying children with Tinea capitis, training for schoolteachers might prove cost-effective in early identification and control of possible outbreaks. Further research in this field is required to shed some more light on this matter and to assist in the development of appropriate policies for controlling Tinea capitis among schoolchildren in the City of Maputo, Mozambique.

\section{ACKNOWLEDGEMENTS}

The authors would like to thank all the school children and School Officers who made this study possible and also all the staff from the Community Health Department of the Mozambican Ministry of Health. Finally, many thanks also to the study sponsors, namely SIDA/SAREC.

\section{REFERENCES}

1. Amorim F, Sidat M, Beatriz C. Tinea capitis in street-children of Maputo, Mozambique. Journal de Mycologie Medicale 11: 92-94, 2001.

2. Elewski BE. Tinea capitis: A current perspective. Journal of American Academy of Dermatology 42: 1-20, 2000.

3. Fisher FW, Cook NB. Fundamentals of Diagnostic Mycology. United States, WB Saunders Company, Philadelphia, 1998.

4. Higgins EM, Fuller LC, Smith CH. Guidelines for the management of Tinea capitis. British Journal of Dermatology 143: 53-58, 2000.

5. Hung M, Bastardo LM, Bastos R. Agentes causais de micoses superficiais. Revista Medica de Moçambique 5 (suppl 1): 54, 1994.

6. Louw CM, Schulz EJ, Koornhof HJ. Scalp ringworm in black children in rural areas in the northern and eastern Transvaal. The Southern African Journal of Epidemiology and Infection 11: 116-119, 1996.

7. Neves H, Ramos SF, Figueiredo MM. Causative Agents of Ringworm in Lourenço Marques (Mozambique). Dermatologia Tropica, p. 153-158, 1963.

8. Silva-Hunter M. Aspectos generales sobre epidemiologia y profilaxis de las dermatophytosis. In: Torres-Rodriguez JM (ed) Dermatofitos y Dermatofitosis, Laboratórios Dr Esteves S.A. Barcelona, Spain, p: 51-56, 1982.

9. Van Uden N, Neves H. Contribuição para o estudo da flora dermatofítica de Moçambique. Anais do Instituto de Medicina Tropical XVIII: 263-267, 1961.

10. Verhagen AR. Distribution of dermatophytes causing Tinea capitis in Africa. Tropical Geographic Medicine 26: 101-120, 1974. 